\title{
Kwame "Almighty" Akoto, The Supernatural Eyes of God
}

\section{Birgit Meyer}

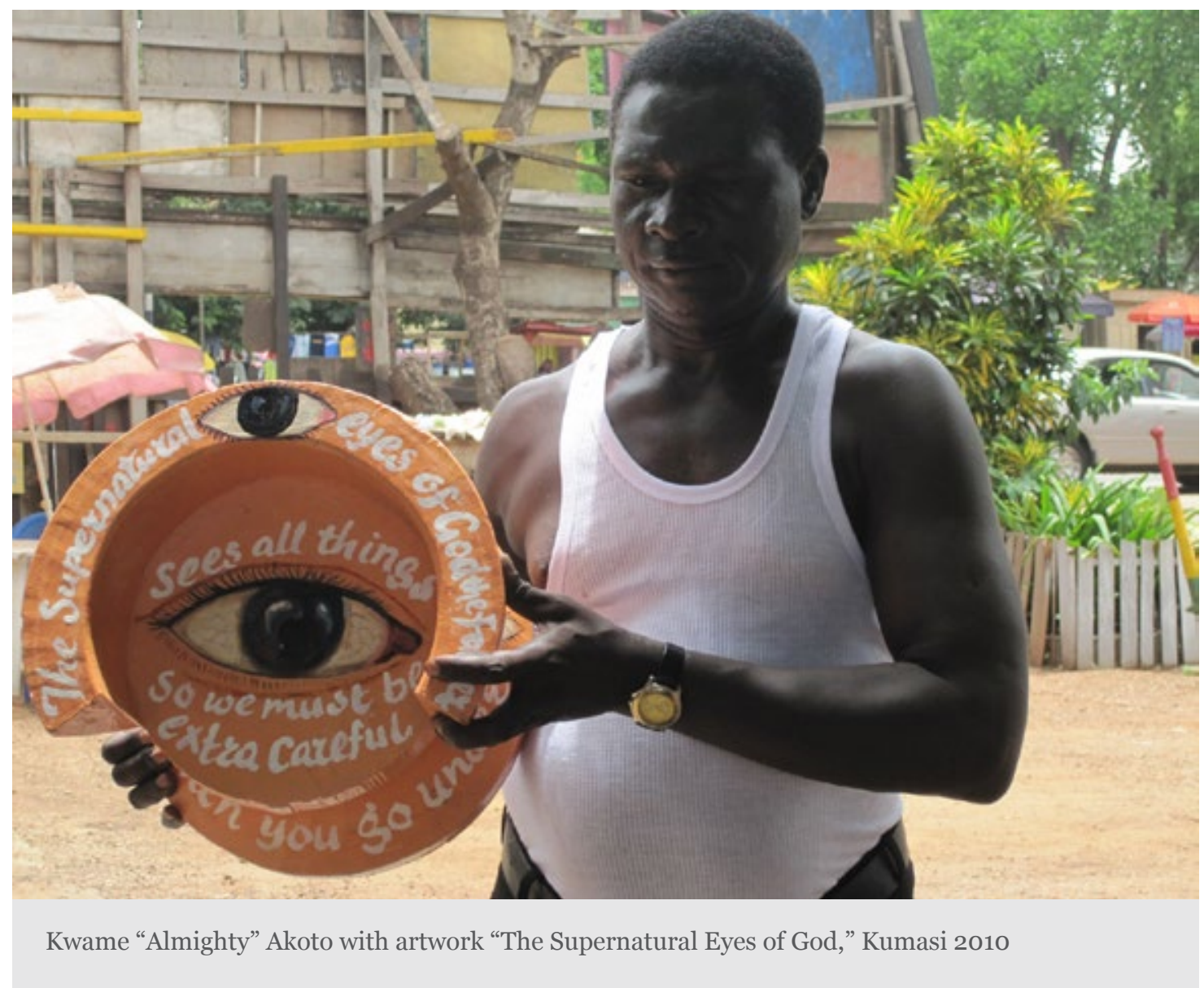

During a trip to Ghana in May 2010, I visited the roadside shop and atelier of painter Kwame Akoto, alias "Almighty," a name he adopted so as to praise the power of God. Approaching the venue, "Almighty God artworks" at Suame Junction, Kumasi, I saw from afar a large picture of the Sacred Heart of Jesus, a painted remediation of Pompeo Batoni's initial eighteenth-century painting that has been mass reproduced over and over again. However, as well as engaging in the reproduction of well-known items of Christian visual culture, Almighty also produces compelling artworks that express his pious Christian attitude in his own original way. This remarkable creativity made him famous as a popular painter in art circuits outside of Ghana. Inside the workshop, my eyes were immediately drawn to a piece of art that Almighty had just finished: a partly damaged mortar, part of a mortar and pestle, from his wife's kitchen, painted in light apricot, and depicting eight more or less big eyes together with the following text, which is scattered over the whole object:

The Supernatural eyes of God the Father

Sees all things.

So we must be extra careful. 
When you go under the sea, the great eyes have seen you.

I am afraid of the eyes of God

If you hide under a mortar God have seen you

God saw you be careful

While this object is unique, its textual message and the motif of the eye resonate with a widely shared emphasis on vision in popular Christianity. The visible and tangible world-"the physical"-is held to be entangled with the "spiritual realm" that remains invisible to the ordinary eye. Gaining insights into how the latter impinges on the former-which may entail either mishap or blessings-requires some kind of supervision-or, as it is called in the context of indigenous religious traditions, a second pair of eyes. In a world in which people are convinced that there is indeed more there than what meets the eye, supernatural vision is in high demand. Faith in God, local Christians stress, makes it possible to achieve the Spirit of Discernment, allowing believers to adopt the eye of God so as to penetrate beyond the level of mere appearance and to see into the spiritual realm. Such vision, cultivated through fasting and prayer, is one of the trademarks of successful preachers. But it is also available to ordinary believers. The tuning of the senses, especially vision and touch, is central to Christian practice. To use David Morgan's term, engaging in authorized "looking acts" as part of spiritual exercise shapes religious subjectivities and sensibilities. ${ }^{1}$

However, Christians are not only able to see like God, but are also seen by God. Almighty's message emphasizes the potentially terrifying aspect of the omnipresent and totalizing divine gaze; the text addresses people directly and warns them to be "careful" because nothing escapes God's attention. The juxtaposition of words with numerous painted eyes dramatizes the message that one is always subjected to God's eyes. Simply by looking at this object covered in aggressive, penetrating eyes, beholders are made to recognize that they both see and are seen. Words and images reinforce each other-a representational strategy through which the message is vested with truth: "God saw you." The fact that Almighty used a spoiled mortar, employed for years by his wife to pound fufu (a highly popular dish made from cassava and/or plantain) enhances the sharpness of his statement. Even a heavy object like a mortar, with its thick walls, cannot be a hiding place. No secrecy is possible. The spoiled mortar is not simply a neutral object to display Almighty's textual-pictorial message. By virtue of its materiality and its past (no doubt heavy) use as the result of which it eventually broke, the spoiled mortar lives on as an artwork that exemplifies the truth of the message it carries. For me as a researcher this is a precious piece-now placed in my study-that alerts me to the material, visceral, and sensorial dimension of Christianity in Ghana and its internal dynamics of claiming truth.

(C) Birgit Meyer 


\section{Citation Guide}

1. Birgit Meyer, "Kwame 'Almighty' Akoto, The Supernatural Eyes of God," Object Narrative, in Conversations: An Online Journal of the Center for the Study of Material and Visual Cultures of Religion (2014), doi:10.22332/con.obj.2014.29

Meyer, Birgit. "Kwame 'Almighty' Akoto, The Supernatural Eyes of God." Object Narrative. In Conversations: An Online Journal of the Center for the Study of Material and Visual Cultures of Religion (2014). doi:10.22332/con.obj.2014.29

\section{Notes}

1. David Morgan, Visual Piety: A History and Theory of Popular Religion Images (Berkeley and Los Angeles: University of California Press, 1998), 8.

\section{Yale}

